IFAS Extension

\title{
Healthy Eating: \\ Improve Nutrition with Food Stamps ${ }^{1}$
}

Linda B. Bobroff ${ }^{2}$

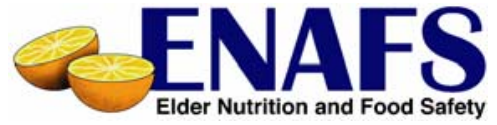

The Food Stamp program is one of several nutrition programs that can help people eat healthful diets. In Florida there are about half a million older adults eligible for Food Stamps who do not receive them. If you think you may be eligible, please call the Elder Help Line (1-800-963-5337) today and ask for more information and help with applying.

\section{What are Food Stamps?}

Food Stamps help people with limited resources buy healthy foods. The U.S. Department of Agriculture (USDA) provides Food Stamps to eligible persons of all ages.

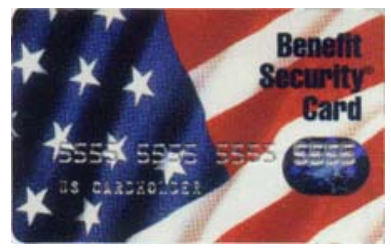

Today they are not in the form of "stamps." They are provided as an easy-to-use Benefit Security ${ }^{\circledR}$ Card, commonly called an EBT (Electronic Benefit Transfer) card. The EBT card is secure, and is widely accepted.

\section{Isn't this "Welfare"?}

No! The Food Stamp Program is a USDA nutrition program. Food Stamps help people with limited resources have a healthy diet. Everyone deserves to have enough to eat, and foods that they enjoy.

\section{How Much Can I Get?}

The minimum amount you can get each month is $\$ 10$. Even this can help you buy quite a bit of food. Below is an example of what just $\$ 10$ can buy. And you may be eligible for more than the minimum!

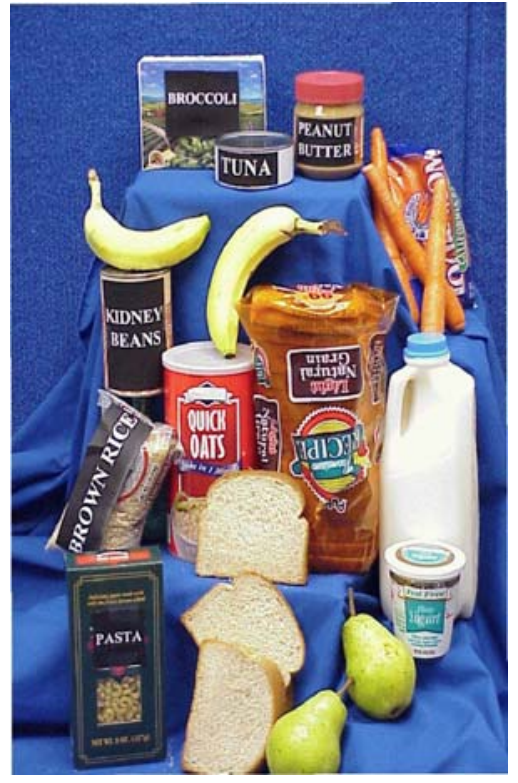

Broccoli

Tuna

Peanut Butter

Two Bananas

and Two Pears

Kidney Beans

Quick Oats

Loaf of Bread

Carrots

Brown Rice

Milk

Pasta

Yogurt

1. La versión en español de este documento es Alimentación Saludable: Mejore su Nutrición con Cupones de Alimentos (FCS8837-Span). This document is FCS8837, one in a series of the Department of Family, Youth and Community Sciences, Florida Cooperative Extension Service, IFAS, University of Florida, Gainesville, FL 32611. First published: January 2007. Please visit the EDIS Website at http://edis.ifas.ufl.edu.

2. Linda B. Bobroff, PhD, RD, LD/N, professor, Department of Family, Youth and Community Sciences, Florida Cooperative Extension Service, Institute of Food and Agricultural Sciences, University of Florida, Gainesville, FL 32611. 